\title{
Left by the West? Academic Discourse on Corruption for a Better Social Resilience
}

\author{
Bohuslav Pernica ${ }^{1}$, Marcel Pikhart ${ }^{2 *}$ \\ ${ }^{1}$ Faculty of Economics and Administration, University of Pardubice, Czech Republic \\ ${ }^{2}$ Faculty of Informatics and Management, University of Hradec Kralove, Czech Republic
}

\begin{abstract}
The paper deals with the topic of corruption that has been understood as a global social problem since the 1990s. Its theoretical background is rooted in the theory of social constructivism. Social constructivism highlights the social strategy in which increased social discourse about a particular topic implies and reflects a growing interest of the society in the topic to arouse a robust awareness of the issue as a social problem. It analyses academic journals and conference paper proceedings that appear in a well-known database of academic journals and texts, namely in Web of Science. The research follows PRISMA methodology and it was conducted as an analysis of the terms and collocations that are connected to the issue of corruption with the aim to identify relevant research papers which have appeared in Web of Science since 1995. The idea behind this analysis was not only to identify the journal papers and papers published as conference proceedings but to compare the results geographically with well-known officially acknowledged state and government data dealing with the issue of corruption, and then to look for connections between these two areas, i.e. academic and governmental data. The results show significant differences between postcommunist countries versus the so-called West regarding how they present information about corruption in their academic discourse. Despite the fact that the West supports the East in its fight with corruption economically, it is not reflected sufficiently and adequately in the relevant academic discourse. This paper suggests that societal resilience against corruption can dramatically be supported by enhanced academic discourse about the topic that is still not sufficient.
\end{abstract}

\section{Keywords:}

Corruption;

Discourse Analysis;

Post-Communism;

Social Constructivism;

Sustainability;

Societal Resilience.

\section{Article History:}

$\begin{array}{llll}\text { Received: } & 06 & \text { January } & 2021 \\ \text { Revised: } & 02 & \text { March } & 2021 \\ \text { Accepted: } & 12 & \text { March } & 2021 \\ \text { Published: } & 01 & \text { April } & 2021\end{array}$

\section{1- Introduction}

The collapse of communism raised closer attention to the issue of corruption in the 1990s. In particular, international organizations, such as the Organization for Economic Cooperation and Development (OECD), the International Monetary Fund (IMF), and the United Nations (UN), systematically provide their financial international development aid, and this effort has addressed the challenge of corruption in countries receiving this aid. Supported by the most generous donor nations, such as the US, Japan, and Germany, they set an anti-corruption agenda and promote it as a global sustainable development strategy. Moreover, a significant sample of countries started to be annually compared by various assessment tools, such as the Corruption Perception Index (CPI), the Worldwide Governing Indicators (WGI) in the 1990s, to provide investors and governments with a compass of risk for corruption assessment of a particular country.

The progress in counter-corruption activities done in post-communist countries after the collapse of communism 30 years ago seems to be rather limited. Embezzlement of European money by oligarchs in Central and Eastern Europe is

\footnotetext{
*CONTACT: Marcel.pikhart@uhk.cz
}

DOI: http://dx.doi.org/10.28991/esj-2021-01266

(C) 2021 by the authors. Licensee ESJ, Italy. This is an open access article under the terms and conditions of the Creative Commons Attribution (CC-BY) license (https://creativecommons.org/licenses/by/4.0/). 
common in particular countries. In the three out of four V4 countries that experienced the integration into the West in 1999 by the NATO enlargement, the public started to elect populist movements (often managed as business projects) into their parliaments as a response to omnipresent corruption. After 2010, corruption started to become a systemic one $[1,2,3]$, and populists at power, such as V. Orbán, A. Babiš, and J. Kaczyński, keep reinforcing their power by means of clientelism and nepotism, instead of accepting measures with the aim of eradicating corruption. Systemic corruption is not an issue of ordinary people, by contrast, it is organized by people having an academic degree who often act as political and economic elites in their countries and who often gained their education in the West [4]. Also, looking for a magic formula for supersession of culture of corruption in post-communist countries after their 30 years of societal and economic transformation, post-communist countries have to get more education for young adults as MungiuPippidia [5] stated for Romania, the EU country where EU citizens are affected by corruption in their daily lives most frequently [6].

Therefore, the academics [7] in post-communist countries should provide us with more research into corruption in order to equip new generations with better knowledge of corruption. In fact, their effort should be more integrated with research done by their colleagues in the West in order to set the underrated issue of corruption in the post-communist environment into the focus of upcoming young elites as an object of prestigious research supported by free-handed financial support provided by prestigious scientific institutions. Hence, the aim of this paper is to assess the effort in publishing knowledge on corruption done by scholars from the Western and post-communist countries in the GRECO, i.e. a European institution established in 1999 by the Council of Europe in order to monitor states' compliance with the organisation's anti-corruption standards, since the start of the economic transformation in the 1990s.

\section{2- Problem Statement}

In response to the EU enlargements linked to the redistribution of public money within the EU financial mechanism, corruption matters in the EU as well [8], in particular, with the adoption of the Stockholm Programme in 2010 [9]. Eleven of the $27 \mathrm{EU}$ countries are post-communist ones (22\% of the EU population) where corruption is informally considered as an ingredient of their local culture or a dark legacy of communism, i.e., it is perceived as cultural programming that developed during the decades of the reign of communist ideology [10]. According to the last Special Eurobarometer on corruption [6], corruption is a substantial social problem for the population post-communist EU countries in particular.

According to the theory of social problems, [11] corruption is considered by social objectivism as a social problem per se. In this point of view, a social problem is (1) a condition (2) affecting a significant number of people in (3) ways considered undesirable, about which it is felt (4) that something can be done through (5) collective action. Although corruption is considered as an objective problem when points 1-4 are met, in accord with the definition, any change to collective action [12] is conditioned by the power of actors involved in a social problem resolution. In democracies, those actors are always governments. Moreover, corruption, as a social problem with the grave impact on a large population, has developed into a global social problem that needs to be addressed in a comprehensive and feasible manner, and as Klitgaard [7], a pioneer of studies on corruption as a global challenge, called upon, there is an increased societal request for substantial academic involvement in this topic.

Apart from the academic discourse, there are many options for how to address the issue of corruption in public, such as whistleblowing, and these new ways of drawing attention to the problem are promoted by well-established institutions, such as the EU. Whistleblowing has proved to be a potent method when there is a need to report a corruption situation [13]. Besides, controlling corruption may be useful for improving political stability in the given region [14] because it is a generally accepted idea that the abuse of public resources is a phenomenon significantly contributing to the worsening of a social climate and leading to a deterioration of the economic foundations of society. In addition, any anti-corruption strategy must be driven with respect to significant gender and generational differences within the population [15]. Anticorruption efforts have been reported to have a very positive effect on corporate social responsibility as well [16]. Moreover, the ability of a society to cope with corruption contributes to the sustainability of society. The imperia have always perished primarily by the decay of the society from within - this moral and mental decay led to a deterioration of the societal cohesion and consequently to a collapse.

In particular, academics in liberal democracies ought to take on research into corruption to support the anti-corruption effort of the government. Thus, academic discourse about this topic should increase the social resilience against corruption because - as social constructivism claims - any kind of discourse delivered to the public arouses and keeps its awareness of the issue. Furthermore, this effort of academics is considered individual support of the global network of institutions covered by the UNCAC Coalition of Civil Society Organisations. Moreover, academics shape the future elite at universities and in society generally so that their research activities may have a significant potential to contribute to better socialization of younger generations and will create their social resilience [5].

Nonetheless, the question is why should institutions under the control of corrupt populists in post-communist countries support this research topic? In fact, it has been a weak awareness of systemic corruption which brought the populists to power. On the one side, it was always desirable to bring the topic of corruption into academic institutions 
in order to give it a mighty clung in the public as both Klidgaard from the West and Mungiu-Pippidia from the postcommunist environment called for; on the other one, scholars doing such as research in their countries have not constituted a mainstream. Irrelevance of corruption topics in the Western countries scoring well in the CPI, WGI, and other indices established in the 2000s and measuring the quality of governance over the World is not a defect because of stability of anti-corruption culture there. By contrast, this situation erects bars of some kind in countries getting into the stage of systemic corruption where some large cities have been affected by it [3] and corruption has never been listed by the central authorities as antisocial behaviour [17]. Likewise, the situation when defence policy is shaped by members of the national lobbyist association [18] can hardly be seen as a common one in the West. Hence, a substantial awareness of issues of corruption is needed in order to attack and clean up the system (an institution) affected by systemic corruption as Klitgaard [19] suggests.

From this point of the view, the state-of-the-art scholars doing their research into corruption are needed as a capability for generating young adults with the potential of not becoming involved in the existing corruption culture. Their status as state-of-the-art experts is indicated by their recognition by the international audience. The most significant and prestigious reconditions which these experts can gain is to recognize by journals indexing in the Web of Science (WoS) database. Also, WoS the best vehicle for backing the scholars dealing with such a sore issue as (systemic) corruption is.

Therefore, this paper focuses on the extent of academic involvement in research into corruption in the period of 1995-2020 (including both 1995 and the first half of 2020) as it can be analysed from a well-established database of academic journals and conference proceedings (i.e., WoS). Focusing on a panel of GRECO countries [20] containing $27 \mathrm{EU}$ nations and 23 others declaring themselves attached to the European civilization values, the paper provides an analysis of academic involvement in research into corruption in the nexus with the ranking of these countries in the WGI (Control of Corruption/CC) [21] that cover the period of this study. In general, the WGI captures six key dimensions of governance contributing to the development of society. The occurrence of the topic of corruption in academic discourse will be linked to the $\mathrm{CC}$ indicator in order to disclose how this academic discourse is linked to the corruption awareness in the given countries. Tables 1 and 2 show the performance in the CC ( -2.5 means the worst ability of a government to control corruption; +2.5 means the worst ability of a government to control corruption) in the GRECO group East/West, 1996-2019, but the GRECO nations Monaco (2007) and San Marino (2010) are not included due to the missing indicators in the WGI.

Table 1. The performance score in the Control of Corruption (Worldwide Governance Indicators), the GRECO group East, 1996-2019.

\begin{tabular}{|c|c|c|c|c|c|c|}
\hline Country & Membership Since & 1996 & 2006 & 2012 & 2019 & $\begin{array}{c}\text { Assessment } \\
\text { (a difference between 2019 and 1996) }\end{array}$ \\
\hline Bulgaria & 1999 & -0.362 & -0.071 & -0.228 & -0.155 & $0.207 b)$ \\
\hline Romania & 1999 & -0.446 & -0.164 & -0.263 & -0.128 & $0.318 b)$ \\
\hline Hungary & 1999 & 0.667 & 0.659 & 0.356 & 0.030 & $-0.637 a)$ \\
\hline Slovak Republic & 1999 & 0.218 & 0.422 & 0.097 & 0.327 & $0.109 \mathrm{c})$ \\
\hline Lithuania & 1999 & 0.421 & 0.162 & 0.394 & 0.676 & $0.255 \mathrm{~d})$ \\
\hline Poland & 1999 & 0.708 & 0.274 & 0.663 & 0.603 & $-0.105 a)$ \\
\hline Georgia & 1999 & -1.527 & 0.044 & 0.401 & 0.668 & $2.195 \mathrm{~d})$ \\
\hline Slovenia & 1999 & 1.114 & 1.034 & 0.840 & 0.906 & $-0.208 c)$ \\
\hline Estonia & 1999 & 0.449 & 1.020 & 1.096 & 1.542 & $1.093 \mathrm{~d})$ \\
\hline Bosnia and Herzegovina & 2000 & -0.271 & -0.302 & -0.304 & -0.613 & $-0.342 a)$ \\
\hline North Macedonia & 2000 & -0.614 & -0.367 & -0.041 & -0.409 & $0.205 b)$ \\
\hline Croatia & 2000 & -0.579 & 0.079 & 0.010 & 0.126 & $0.705 \mathrm{~d})$ \\
\hline Latvia & 2000 & -0.203 & 0.370 & 0.245 & 0.485 & $0.688 \mathrm{~d})$ \\
\hline Moldova & 2001 & -0.437 & -0.642 & -0.614 & -0.619 & $-0.182 a)$ \\
\hline Albania & 2001 & -0.894 & -0.804 & -0.727 & -0.529 & $0.365 b)$ \\
\hline Czech Republic & 2002 & 0.683 & 0.357 & 0.272 & 0.506 & $-0.177 a)$ \\
\hline Serbia & 2003 & -1.140 & -0.293 & -0.330 & -0.446 & $0.694 b)$ \\
\hline Azerbaijan & 2004 & -1.446 & -1.090 & -1.127 & -0.868 & $0.578 b)$ \\
\hline Armenia & 2004 & -0.473 & -0.671 & -0.588 & -0.184 & $0.289 b)$ \\
\hline Ukraine & 2006 & -1.110 & -0.751 & -1.077 & -0.709 & $0.401 b)$ \\
\hline Montenegro & 2006 & 0.000 & -0.402 & -0.112 & 0.030 & $0.030 \mathrm{c})$ \\
\hline Russian Federation & 2007 & -1.053 & -0.911 & -1.042 & -0.832 & $0.221 b)$ \\
\hline Belarus & 2011 & -0.390 & -0.620 & -0.517 & -0.060 & $0.330 \mathrm{~b})$ \\
\hline Kazakhstan & 2020 & -1.133 & -0.992 & -0.919 & -0.320 & $0.813 b)$ \\
\hline
\end{tabular}

a) a deterioration; b) a progress, yet not able to control corruption; c) no significant progress in controlling corruption; d) a shift to the West 
Table 2. The performance score in the Control of Corruption (Worldwide Governance Indicators), the GRECO group West, 1996-2019.

\begin{tabular}{|c|c|c|c|c|c|c|}
\hline Country & Membership since & 1996 & 2006 & 2012 & 2019 & $\begin{array}{c}\text { Assessment } \\
\text { (a difference between } 2019 \text { and 1996) }\end{array}$ \\
\hline Greece & 1999 & 0.339 & 0.364 & -0.189 & -0.012 & $-0.351 \mathrm{a})$ \\
\hline Spain & 1999 & 1.129 & 1.186 & 1.128 & 0.647 & $-0.482 a)$ \\
\hline Cyprus & 1999 & 1.331 & 1.093 & 1.251 & 0.604 & $-0.727 a)$ \\
\hline France & 1999 & 1.247 & 1.464 & 1.456 & 1.301 & 0.054 \\
\hline Belgium & 1999 & 1.360 & 1.310 & 1.608 & 1.552 & 0.192 \\
\hline Ireland & 1999 & 1.709 & 1.710 & 1.464 & 1.458 & $-0.251 c)$ \\
\hline United Kingdom & 1999 & 1.981 & 1.792 & 1.674 & 1.775 & $-0.206 \mathrm{c})$ \\
\hline Iceland & 1999 & 1.733 & 2.183 & 1.886 & 1.708 & $0.025 c)$ \\
\hline Germany & 1999 & 1.905 & 1.803 & 1.830 & 1.895 & $-0.010 \mathrm{c})$ \\
\hline Luxembourg & 1999 & 1.951 & 1.883 & 2.123 & 2.112 & 0.161 \\
\hline Sweden & 1999 & 2.174 & 2.197 & 2.313 & 2.118 & $-0.056 c)$ \\
\hline Finland & 1999 & 2.207 & 2.465 & 2.235 & 2.153 & $-0.054 c)$ \\
\hline United States & 2000 & 1.571 & 1.353 & 1.411 & 1.215 & $-0.356 c)$ \\
\hline Denmark & 2000 & 2.231 & 2.470 & 2.381 & 2.107 & $-0.124 c)$ \\
\hline Malta & 2001 & 0.479 & 1.010 & 0.943 & 0.239 & $-0.240 a)$ \\
\hline Netherlands & 2001 & 2.082 & 2.050 & 2.118 & 1.999 & $-0.083 c)$ \\
\hline Norway & 2001 & 2.139 & 2.134 & 2.256 & 2.073 & $-0.066 c)$ \\
\hline Portugal & 2002 & 1.372 & 1.017 & 0.960 & 0.764 & $-0.608 a)$ \\
\hline Turkey & 2004 & -0.148 & 0.027 & 0.158 & -0.291 & $-0.143 a)$ \\
\hline Andorra & 2005 & 1.318 & 1.260 & 1.268 & 1.234 & $-0.084 c)$ \\
\hline Austria & 2006 & 1.732 & 1.915 & 1.390 & 1.881 & 0.149 \\
\hline Switzerland & 2006 & 1.987 & 2.093 & 2.147 & 1.997 & 0.010 \\
\hline Italy & 2007 & 0.408 & 0.484 & 0.066 & 0.239 & $-0.169 a)$ \\
\hline Liechtenstein & 2010 & 1.318 & 1.260 & 1.801 & 1.968 & 0.650 \\
\hline
\end{tabular}

a) a deterioration; b) a progress, yet not able to control corruption; c) no significant progress in controlling corruption; d) a shift to the West

Comparing Table 1 with Table 2 with a difference between 2019 and 1996 score, it is vivid that the West countries perform in the CC usually better than the post-communist ones in essence. Although a deal of the GRECO group West members dropped in their score, a substantial majority of the GRECO group East has not yet achieved a positive score during their 25-year development. With exception of Baltic nations, Georgia, and Croatia, there has been no significant shift to the West.

\section{3- Research Design}

The idea underlying the paper is based on the theory of social problem as social constructivism and public arenas model [22] where a collective action could be initiated only when the problem attracts so public attention that it will disappear due to tackling it the collective action. In this opinion, social problems need management shifting the problem over different arenas. One of them might the arena of scientific communication trough indexed papers in SCOPUS [23] or WoS. Also, a global social problem such as ecological or economic transformation and corruption has to be reflected by social discourse in as many arenas as possible to keep an adequate awareness and response of the government to the issue. So, intensive public discussion snowballs more relevant actors keeping public awareness of corruption as detrimental for society and economy, indoctrination of young adults against corruption during their tertial education, etc. is the strategy included in the UN Coalition Against Corruption (UNCAC) strategy. Hence, universities may be seen as a link in the UN global effort [24, 25] intervening there where corruption became a part of culture [26].

\section{3-1- An Arena Model and Academics as Movers of Corruption Topics}

The theoretical foundation of the research is based on a social constructivism model. The idea behind social constructivism is the fact that those who give advice and publish on the topic also influence public opinion and are natural opinion-makers in the academic, political, and general societal context. Those opinion-makers set the agenda in relevant arenas and attract the attention of key decision-makers. 
According to the definition of a social problem [11], the social problem may be to tackle when only the government would bear it in the mind in order to set this problem as a governmental agenda. However, lenience to corruption exists in post-communist countries and it is a widespread issue silently tolerated or even accepted by the majority in the society $[2,10]$. Additionally, there is a significant number of people affected by the problem, but those people are accustomed to the undesirable conditions usually not tolerable in the West democracy. To encourage significant actors to collective action, something must be done to draw their attention to points 3 and 4 in the definition of a social problem in accordance with the theory of social objectivism. In this point, some actors of social policy might seize the problem of corruption in the frame of social constructivism, and the problem can rise and fall through a system of public arenas [22] to solve it by means of legitimate collective action, e.g. by a new government elected by the dissatisfied electorate. In this opinion, any social problem must be kept in public awareness as much as possible. In particular, any public agenda colliding with private interests hidden in the government (corruption) must be maintained in so many arenas as possible in order to prevent an utter suppressing of the topic's presence in the public space.

Powerful vehicles for this effort are usually considered academics as stated by Mungiu-Pippidia and Dusub [5], Romanian scholars who propose academic anti-corruption activism in their post-communist EU country and who share their knowledge in the global academic arena. Hence, there is always a will of governments to tackle these issues to prevent the society from decline and decay, and the academic society in charge of knowledge on the nature and societal phenomena, in general, can contribute significantly to the collective action requested to tackle the social problem of corruption. As noticed by Mungiu-Pippidia, academics usually contribute to such an agenda by their academic activities, i.e., their research and related academic discourse, such as conferences and journal papers. Their research is usually implemented into educational activities and curricula to ensure the modernization of society via generation and idea rotation. Therefore, the arena of scientific communication composed of journals and conferences is an inseparable element of public discourse on corruption because it indicates that the matter is considered of great importance as well as crucial to the society that attempts to address this issue by academic or public attention and awareness.

Being hold by the public in high esteem, the public arenas model is often shaped by academics enjoying the freedom of free speech, and it is also crucial to realise that they are essential opinion-makers in society. However, their most professional and target-oriented discourse appears mostly in academic journals and conference proceedings. Therefore, their public engagement at the national level is a momentous spin-off derived from their cutting-edge research. Moreover, the discourse of corruption can be offered to university students, the future national elite in business and public institutions, as well as in university courses through curricula [25] to draw the students' attention to the problem. An investigation of the issue of corruption by people in the age when they are still open to socialization during their education may contribute to their increased awareness of the problem of corruption in their own country. In addition, scholars dealing with corruption in their research support the counter-corruption policy at many levels of state organizations. It does not matter if this scientific effort is done on demand and for profit or it is done on behalf of humanity and social responsibility. In summary, public and academic discourse about corruption leads to increased awareness about corruption, and it is always a prerequisite for shaping an effective anti-corruption strategy.

The approach to the issue of corruption can be cross-disciplinary, i.e., based on several disciplines so that the problem can be addressed more efficiently [15]. Other research indicates that to stop employees from engaging in corruption, it is important to strengthen the ethical climate in the organization and encourage ethical decision-making processes by stressing the wellbeing of other people in the organization [27]. This approach is rather based on subjective satisfaction feelings caused by ethical behaviour, but it seems promising in curbing corruption as well. This paper claims that almost any intentional activity is beneficial and crucial to tackle the problem of corruption, and academic discourse is one of the relevant approaches as academics are opinion makers and they are also responsible for shaping the next elites by their education. To strengthen the resilience of European societies against the risk of their decay by corruption, academics are not substitutable in the effort against corruption due to the fact that more than half of the young age group in the European countries continues their educational development at universities. Therefore, academics have a unique opportunity to influence and shape this future elite by their academic discourse.

\section{3-2- Research Question}

Therefore, the research question focuses on how much attention there is towards corruption in the West compared to the East when considering academic discourse, i.e., the relevant academic sources, such as journal papers on the topic of corruption.

\section{4- Methodology}

\section{4-1- Controlling Corruption within GRECO}

As already presented, the GRECO countries are split into two groups reflecting the post-communist culture (the group East) and the rest (the group West). Thus, this split facilitates an assessment of the CC score in order see the difference in the anti-corruption effort done by the post-communist and other GRECO countries. 
The WGI CC score is an assessment of the national experts asked by the World Bank to assess the situation in their countries regarding governmental capability to cope with corruption. Hence, we can assume that experts contributing to the WGI have an academic background as professors. The CC score reflects the presence of the social problem of corruption in a particular country.

\section{4-2- WoS as a Global Arena of Academic Communication within the GRECO}

WoS represents the global (central) arena for the GRECO region and this arena is followed by national (peripheral) arenas. Some geographically national or peripheral arenas are very distant from the global or central arenas, and even if the topic of corruption is crucial for these countries, they still do not appear in the global arena, i.e. WoS. On the contrary, scholars from these peripheral arenas should participate in the prestigious and global WoS arena to increase the awareness of the topic through this academic discourse. In summary, the central arena constructs a line of research, i.e., the mainstream, acknowledged by publications of scholars from the peripheral arenas. Moreover, a lack of prestigious national research on corruption and the weak performance of a nation in its ability to control corruption is considered as a failure of academics.

The WoS score of scholars affiliated either to the Western or Eastern cultural domain was selected as an indication of prestige. Also, we may employ other databases indexing the scientific effort of scholar across the world, but what would be worthy such effort? The appearance of the paper dealing with corruption issues in a national journal does not improve the situation of scholars aspiring to get funding for their beneficial research. These publications can hardly bring a success in getting funds for independent research setting the agenda against corrupt governments in the postcommunist countries.

Thus, scoring in WoS is seen as each scholar's shield against to get "a dissident" in the field of expertise which is really beneficial to the society on the one hand, on the other one, it is hard to expect that these experts would get openhanded national grants for an investigation of issues colliding with oligarchic interests in the government. After all, science is a business as usual and only scientists with the best publication score, with the most substantial impact in the world, are usually worthy of public support. - The "publish or perish" slogan is the best pacifier in the debate on a public support of research with contentious impact as research into corruption is. Following the opinion, it does not make any scientific sense to the extent the research into other databases enshrining knowledge of humankind acquired by the effort of scholars over the world. To overstate this situation, research into corruption may sometime jeopardize the investigator's bread and butter.

\section{4-3- The Academic Discourse from the Point of the View of Time and Space}

In order to answer the research question, the paper follows the standardized PRISMA 2009 methodology for systematic reviews and meta-analyses [28]. The essential rationale of this paper was to analyze the literature on the topic of corruption in a generally acknowledged database of academic texts, namely, the texts that appear in WoS. Also, we assume that scholars in more affected countries by corruption should be more productive. Firstly, recognizing the anticorruption agenda as the agenda pushed from outside by the power of international organization and initiatives, such as GRECO, scholars should act as experts in corruption for international organizations. So, they speak English as well as they are able to apply for international grants where subsidizing institutions usually request visibility of the results originated by their financial support. Secondly, such as international backing prevent these distinguish scholars from becoming "dissidents". In order to fight corruption, each country needs an intellectual capacity. On the other hand, why this capacity would be supported by the central government in the most corrupted countries? Also, rational scholars usually choose non-controversial topics ensuring them instant prosperity.

The chronological and geographical dispersion of the papers was divided based on two parameters:

- Period in individual years, i.e., 25 years, altogether divided into four periods (1996-2005, 2006-2011, 20122017, 2018-2020) reflecting the availability of WDI data.

- Geographical area, i.e., the continents and the state of the author divided simply into the East and West - the reason for this division was to follow the same categorization followed by the WGI in the GRECO panel.

English was selected as the scientific language franca. In the beginning, we wanted to take into account other languages but a majority of publisher houses covering the WoS journal allows to publish only in English, MDPI publisher inclusive. In addition, publishers in post-communist countries prefer English as a shared language securing a broad audience to their publications in order to gain and measure a global impact of journals in accordance with the methodology set by private owners of the databases. Also, the main focus of research could not be communicated in local arenas using minority languages, but the global arena highlighting English as a universal language. Therefore, the cluster yielded by the search process can be considered as the global arena for academic discourse on corruption in general. 


\section{4-4- Data Collection}

The search period in WoS was restricted to years from 1995 to 2020. To test and analyze the occurrence of the papers that are related to the topic of corruption, the keyword search was conducted focusing on the following words and collocations by using standardized Boolean operators. The search words were corruption AND bribery, corruption AND bribe, corruption AND backhander, corruption AND collusion, corruption AND fraud, and corruption AND embezzlement. Any of these words or collocations could appear in the title of the paper, keywords of the paper, or the abstract of the paper, which guarantees an exhausting coverage of the topic of financial corruption as it is described and analyzed by academic discourse, leaving out the topic of corruption with its larger meaning in the humanities, social science, ICT, etc. This search yielded publicly available information that could be readily quantified and evaluated by standardized analytical tools.

Cumulative results about the number of papers were obtained from WoS in the years 1995-2020 (including the year 1995 and the first half of 2020). The search was conducted in June 2020; therefore, it is assumed that the vast majority of the papers, or ideally all of them, from the year 2019 had already been published before the search. After generating the results, the papers were manually checked regarding their relevance to and correspondence with the researched topic.

The inclusion criteria were as follows:

- Only journal articles and international conference papers were included;

- Only papers written in English were included;

- Only peer-reviewed papers were included;

- Only papers published in the years from 1995 to May 2020 (including both 1995 and 2020) were included;

- Only papers complying with the search words above were included;

- Only GRECO panel countries presented in Table 1 and Table 2;

- These areas were included: Social Sciences, Economics, Econometrics and Accounting, and Business, Management and Accounting.

The exclusion criteria were as follows:

- The studies dealing with the topic of corruption from other perspectives, i.e. non-financial corruption;

- The studies dealing with corruption with other meanings (the metaphorical meaning of corruption, technical meaning of corruption, information technology meaning of corruption, etc.);

- Books, book chapters, and book reviews were excluded;

- These systematic areas in WoS were excluded: Arts and Humanities, Medicine, Environmental Science, Psychology, Engineering, Mathematics and Computer sciences.

To obtain reliable and verifiable results, it was necessary to establish a control sample to obtain comparable data from WoS on another grave social issue, particularly economic transformation, which is generally considered as a broader topic than corruption. It is important to mention that controlling corruption is perceived as a precondition of a successful economic transformation, but it remains just one of the other significant issues in transforming postcommunist countries, yet, it is often stressed by international organizations and initiatives, e.g., GRECO. In particular, the control sample was associated with the given collocation to compare the results obtained from the databases connected to the topic of corruption. The key collocation economic transformation results were then compared with the topic of corruption to see if there is any significant discrepancy.

\section{5- Results}

In essence, the division of the East and West remains visible after 30 years of their economic transformation. Hence, it would be nice to know-how is the global issues of corruption covered by scholars in the global arena of communication, i.e., WoS, which is particularly interesting for scholars from post-communist countries. This situation I clear from Table 3 processing the first WoS search without any time limit, i.e., from 1977 to 2020, generated 470 documents, and further refined to the years 1995-2019. This search generated 432 documents and these issues were then exported to a cvs file to be further analyzed.

Table 3 shows that the West is interested in the topic of corruption much more than the East and it may be for several reasons. The West provides financial aid to the East and these countries are the recipients of the aid. Moreover, the postcommunist countries are more corrupt in general, and the reason is rooted in their background, history, and culture of 
these countries. Moreover, the West keeps making an effort to set a new view of corruption in the East countries by financial support, by which the East is trying to converge to the West by their academic publication activities.

Table 3. Distribution of topics, papers, and authors among arenas according to Web of Science database, 1992-2020 (June).

\begin{tabular}{|c|c|c|c|c|c|c|c|c|c|c|c|}
\hline \multirow{2}{*}{ Year } & \multicolumn{4}{|c|}{ Topic focused on } & \multicolumn{4}{|c|}{ The paper issued in a journal in } & \multicolumn{3}{|c|}{ The corresponding author from } \\
\hline & East & West & others & Total & East & West & others & Total & East & West & Total \\
\hline 1992 & & & 1 & 1 & & 1 & & 1 & & & N/A \\
\hline 1993 & & & & 0 & & & & 0 & & & 0 \\
\hline 1994 & & 1 & & 1 & & 1 & & 1 & & 1 & 1 \\
\hline 1995 & 1 & 2 & & 3 & & 3 & & 3 & & & 0 \\
\hline 1996 & & 3 & 1 & 4 & & 4 & & 4 & & & 0 \\
\hline 1997 & 2 & 5 & & 7 & & 7 & & 7 & & 4 & 4 \\
\hline 1998 & & 4 & & 4 & & 3 & 1 & 4 & & 3 & 3 \\
\hline 1999 & & 4 & 1 & 5 & & 5 & & 5 & & 4 & 4 \\
\hline 2000 & 1 & 3 & 1 & 5 & & 5 & & 5 & & 5 & 5 \\
\hline 2001 & 1 & 4 & 1 & 6 & & 6 & & 6 & 1 & 4 & 5 \\
\hline 2002 & & 9 & 2 & 11 & & 11 & & 11 & & 10 & 10 \\
\hline 2003 & & 3 & 1 & 4 & & 4 & & 4 & & 4 & 4 \\
\hline 2004 & & 4 & & 4 & & 4 & & 4 & & 4 & 4 \\
\hline 2005 & & 9 & 2 & 11 & & 11 & & 11 & & 11 & 11 \\
\hline 2006 & & 8 & & 8 & & 8 & & 8 & & 8 & 8 \\
\hline 2007 & & 12 & 1 & 13 & & 13 & & 13 & & 12 & 12 \\
\hline 2008 & & 16 & 2 & 18 & & 17 & 1 & 18 & & 17 & 17 \\
\hline 2009 & & 18 & 2 & 20 & & 20 & & 20 & & 19 & 19 \\
\hline 2010 & & 14 & 4 & 18 & & 18 & & 18 & & 16 & 16 \\
\hline 2011 & 3 & 14 & 3 & 20 & & 20 & & 20 & & 17 & 17 \\
\hline 2012 & 3 & 18 & 5 & 26 & & 26 & & 26 & 1 & 20 & 21 \\
\hline 2013 & 1 & 16 & 5 & 22 & & 22 & & 22 & & 20 & 20 \\
\hline 2014 & 4 & 15 & 6 & 25 & 2 & 23 & & 25 & 3 & 21 & 24 \\
\hline 2015 & 4 & 34 & 8 & 46 & 4 & 41 & 1 & 46 & 5 & 34 & 39 \\
\hline 2016 & 3 & 30 & 5 & 38 & 1 & 35 & 2 & 38 & 3 & 29 & 32 \\
\hline 2017 & 4 & 37 & 1 & 42 & 4 & 38 & & 42 & 8 & 34 & 42 \\
\hline 2018 & 9 & 37 & 10 & 56 & 5 & 50 & 1 & 56 & 7 & 45 & 52 \\
\hline 2019 & 10 & 52 & 15 & 77 & 2 & 72 & 3 & 77 & 5 & 68 & 73 \\
\hline 2020 & 7 & 17 & 3 & 27 & 1 & 25 & 1 & 27 & 6 & 18 & 24 \\
\hline \multicolumn{12}{|c|}{ (1995-2020) } \\
\hline Total & 53 & 388 & 79 & 520 & 19 & 491 & 10 & 520 & 39 & 427 & 466 \\
\hline Share & 0.10 & 0.75 & 0.15 & 1.00 & 0.04 & 0.94 & 0.02 & 1.00 & 0.08 & 0.92 & 1.00 \\
\hline
\end{tabular}

With regards to Table 3, three points have to be highlighted. Firstly, the issues of corruption became a topic for more academics after 2006 when the number of papers started raising. Secondly, the topic of corruption has been usurped by scholars of the West because an overwhelming majority of the papers has been published on corruption in the West, also, a corresponding author came from the West, and the papers were issued in the journal affiliated in the West. Finally, the performance of the scholars of the East remains poor in comparison with their colleagues of the West. In addition, there is a lag of 10 years in comparison with the influx of publications from the West which started in 2007. So, the topic of corruption in the post-communist environment might remain marginalized in comparison with a broader topic which corruption is an inherent part of.

After the year 2014, an increase in papers in eastern Europe ought to be noticed. Post-communist authors have been trying hard, but there is still a vast disproportion in favour of the West. For instance, despite the fact that the USA enjoys a very low corruption index, the number of papers focusing on corruption considerably exceeds the number of papers published by authors of other nationalities. The countries that poorly performed in controlling corruption do not publish much and we can observe a ten-year delay compared to the Western countries. The East countries authors publish in 
global journals, but what is the reason to inform about corruption in the West, it should rather be placed in the East. The East scholars rather remain enclosed in their geographical and cultural environment for decades. Nonetheless, a lot of post-communist countries still receive financial support from the West, therefore they should be interested and active in the research of the topic of corruption much more.

In order to get a benchmark for purposes of discourse analysis, the identical methodology was used for the search: the result search connected to economic transformation yielded about 4000 results, i.e., ten times more than the corruption topics. Is corruption a topic with far less impact than economic transformation which was always a part of it? The areas to which the topic of economic transformation is connected in the WoS category are as follows (the number in brackets indicates the number of papers): Economics (1,402), Geography (785), Environmental studies (776), Environmental sciences (595), and Political science (579), Sociology (450), Urban studies (392). On the other hand, the corruption \& bribery topics are connected to these categories in Web of Science: Economics (158), Business (92), Law (91), Political science (59), Ethics (49), Criminology/Penology (47), Management (41). In principle, corruption is perceived as micromanagement despite the fact that it influences the global environment. However, economic transformation is perceived as an issue of macro-management that influences the global natural environment. The results of the papers dealing with the topics of economic transformation versus corruption and bribery as indexed by WoS in the period of 1990-2019, with the stress on the period of 1995-2020, are presented in Table 4.

Table 4. Papers dealing with the topics of economic transformation and corruption \& bribery, 1990-2019.

\begin{tabular}{|c|c|c|c|c|c|c|}
\hline Topic & prior to 1995 & 1995-1999 & 2000-2004 & 2005-2009 & 2010-2014 & 2015-2019 \\
\hline Economic transformation & 252 & 470 & 535 & 828 & 1,452 & 3,677 \\
\hline Corruption \& bribery & 2 & 23 & 30 & 70 & 111 & 259 \\
\hline $\begin{array}{l}\text { The difference between the first and the } \\
\text { second topic as a multiple }\end{array}$ & 126.0 & 24.4 & 17.8 & 11.8 & 13.1 & 14.2 \\
\hline
\end{tabular}

It must be highlighted that both corruption and economic transformation remain global urgent topics, however, the interest in them differs significantly, and they are not perceived in the global academic agenda as a "yin and yang" topic. The corruption topic gets much lower attention despite the generally accepted opinion that transformation is never isolated from corruption, i.e., it is its natural part. In principle, WGI claims that some countries are not on a sufficiently high level in their fight against corruption, but the same organization issuing the WGI considers their economic transformation as completed. Comparing the inputs given by Tables 1 and 2 with the results of the analysis given by Tables 3 and 4, the topic of corruption lags behind the topic of transformation. According to the results presented in Table 4, the scholars pay 10 times lower attention to the issue of corruption than the issue of economic transformation.

Surprisingly, corruption remains still at the periphery of global attention although it is such a complex phenomenon as the transformation process. The increase of the interest in the topic of corruption after the year 2000 is probably caused by the attention of the public to the topic of environmental issues, despite that fact that these environmentalists are more focused rather on the criticism of multinational corporations and their practices. It must also be noted that environmental exploitation is often seen as a consequence of corruption in society.

\section{6- Discussion}

\section{6-1- Left by the West?}

Despite the fact that the research was conducted in one database only, i.e., WoS, naturally excluding all other databases that could be relevant for the given topic, we claim that the results yielded are relevant and essential to understanding the topic in the given context. The research in its nature was based as discourse research [28] on issues of corruption in the global academic arena represented by scientific communication registered with the WoS database, the most prestigious index of written academic discourse. As presented by Sinay et al. [29], WoS is just the tip of the iceberg because it covers only journals published in English [30]; hence, as the results show, the papers and authors are usually affiliated with the USA. In addition, having a paper indexed in this database does testify nothing about the quality of the contributions. Maybe, there are more high-quality papers in non-English languages and they are read by relevant participants of social discourse and opinion-makers (in the peripheral arenas), but the language is a constraint for their global sharing opportunities and possibilities. Papers indexed by WoS may be written to get scientific prestige in particular, instead of sharing knowledge in general. Taking into account ethical issues, non-English native speakers must not copy the research from WoS into peripheral arenas.

This leads us to a question: Is corruption a national particularity? According to the GRECO approach, its nature is universal based on the presence of human beings in institutions of economy and society. Naturally, there are other databases that aggregate journal and conference papers, but it would not be feasible to process them and there is also no way how to access all papers in a systematic way despite their high relevance for the social and academic discourse 
about corruption. The same applies to bachelor and diploma theses and dissertations. They are also relevant for the topic of academic discourse and should be noted here, but they go beyond the scope of this paper for the same reasons.

The COVID-19 situation in 2020 has clearly confirmed the social constructivism strategy, i.e., when the society considers a particular topic to be important, then there is an increased academic and political attention put into the topic as can be seen by the avalanche of papers on the topic of pandemics throughout the academic discourse starting naturally from medicine and biology, through education and ICT to economics and sociology. Similarly, in the case of corruption, several special issues on the topic of corruption were published and conferences organised. An example of this effort, the regional Kyiv-Mohyla Law and Politics Journal (5) 2019 with the title Legal and Politics Challenge of Anticorruption Activities was published. The UN says that corruption is a global problem, but eventually, the topic stays isolated and regionally bound, which leads to the situation when the voice of these regional journals is not strong enough despite the fact that they use English as their lingua franca for their idea dispersion. The topic of corruption covered by WoS is then quite limited as the journals covered by this database are not from the regions that are fighting the issue of corruption the most. On the contrary, the developing countries, i.e., those that have significant problems with their level of systematic corruption and their academic journals are not visible and their voice is not heard, neither locally nor globally.

The major relief in fighting corruption not only in post-communist countries would be to help academics to be able to publish in global journals rather than merely in local and provincial journals that have very low or no visibility. In fact, there are no journals with an excellent reputation dealing only with the issue of corruption. An immense dispersion of the topic over the publisher houses in the world is determined by commercialization of dissemination businesses [23]. Such as a commercial indexation provides feedback on the individual impact of a scholar's research on the community of academics on the one side; on the other one, it prevents a collective knowledge sharing, e.g., due to a policy of only one author's publication in a journal during a specific period. Hence, the topic of corruption is therefore very isolated in these peripheries and individual states have to fight it themselves, such as the example of Ukraine. Moreover, even if international academics publish in these regional journals, due to the journal's low visibility, there is no global impact of these journals and academics either. In summary, a random presence of famous scholars in a conference on corruption in a post-communist country cannot break up the isolation of national academics. Having a particular open-access journal published by an international organization focusing on corruption issues may sort out the situation of isolation in research on corruption.

Going more into detail, the arena West and East remains rather mutually isolated, which is the result of the "Bradford's law, when a researcher makes an automated search, the results tend to only include articles published in high-impact journals. Hence, despite their quality, papers in journals with moderate to low-impact factors, often in the arts and social sciences, are excluded from consideration by the algorithm" [29]. In this case, researchers look for prestige instead of the knowledge needed for solving the social problem of corruption in their countries. Therefore, "it is important to see that by engaging in academic discursive practices, academics give value to certain knowledges (which are made true as it were). And by defending the value of scientific truths that one understands to be discursively constructed, one can criticize populist ideas as lies, which are accepted by some, especially in nonacademic communities (e.g. NRA supporters, white evangelicals)." [31] That implies a situation in which scholars from Central and Eastern Europe are engaged in getting recognition rather than in supporting the government by developing general awareness about corruption in society.

Publishing in prestigious journals is often considered a good reference for subsidizing further research. Keeping this strategy in mind, post-communist governments sometimes press scholars to publish only in English, although the knowledge of English in post-communist countries still remains relatively low. No surprise that the afore-mentioned Ukrainian special journal issue on corruption was published in English. Furthermore, post-communist universities usually keep failing in the task requested by Klitgaard. As presented by Zaloznaya, Claypool, and Reisinger, it is important to tailor the "anti-corruption policy to specific national and subnational contexts" [32].

It is crucial to realise that "fight against corruption can be fruitful only if approached from multiple standpoints. Aside from developing laws and regulations and other formal institutions, corruption must also be approached from an academic and educational perspective. One first step that universities and business schools can take to align themselves with the international sustainability and anticorruption agenda is by becoming a signatory of the United Nations Principles for Responsible Management Education (PRME). The six principles of the initiative address the responsibilities of higher education institutions in preparing current and future business professionals for the challenge of doing business in a sustainable and responsible way” [25].

\section{6-2- Further Research Ideas}

In the view of the methodology section, another interesting research topic is the question of who supports the prestigious research into corruption. The corruption topic is an international organization's agenda as supported with evidence of the start of the UN International Anti-Corruption Academy in Vienna, Austria, after 2010. Taking into 
account that Austria is a Western country and Vienna is one of the most expensive cities to live in the world, the anticorruption effort is again in progress out of the post-communist environment. Also, the counter-corruption effort may be satirized by post-communist populists at power as "global elitism" which does not deserve to be supported by nations. A similar research topic to suggest would be gender issues. On the one hand, public funding institutions in Europe take into account gender equality in order to balance females in society. On the other hand, post-communist populists usually may not take females scholars seriously. Also, getting capabilities at universities would be contra-productive in "macho societies". The limited progress in controlling corruption in the WGI score in many post-communist countries and in Greece and Turkey done in the last 25 years indicates that the West strategy how to tackle corruption in different cultural environments might be based on incorrect projections. Also, international organizations should more focused not on the issue of how to cope with corruption in the post-communist environment but on the reasons why their approach to it keeps failing.

It is also vital to create institutional networks dealing with the issue of corruption on both a regional and a global level. There are several universities implementing the topic of corruption into their responsible management education [25] trying to incorporate the corruption discourse by which it is possible, in the long-run, to reduce the level of corruption in the society. The fact that universities are active and visible in the regional context, it is important to strengthen the university partnership to create university networks and increase both the local and global visibility of academics. This will lead to the enhanced societal sustainability and the global impact of the topic not only in countries for which corruption is an urgent problem. Because universities are the institutions that shape the values of elites, i.e., they contribute to the culture of a country, the high-corrupted societies need to strengthen their accountability for generally accepted norms instead of relying on the extension of capacity and moral flexibility as presented by Zhang in an experiment [33]. In addition, there is a major task for the universities as well because the universities do have to take care of not being corrupted as well [34].

\section{7- Conclusions}

The social constructivism idea is essential when talking about the topic with a significant impact on the population as the social problem of corruption is. To cope with this problem more successfully, a higher level of public awareness is needed not only to elicit it but to keep it for a long time because corruption is often profoundly rooted in the national culture. So, using the concept of public arenas developed by constructionists in sociology can facilitate a clear indication of insufficient concern of specific population for tackling such as social problems. Moreover, academic discourse about corruption can prove to be even more effective in managing and improving the situation connected to corruption in society as it influences and forms elites that are responsible for societal dynamics and general trajectory.

The current focus of political elites on economic development and sustainability is clearly urgent from a global business point of view, however, the concept of inner transformation of how individuals and societies perceive corruption is crucial for this sustainable economic development. The topic of corruption is now important for sociologists, political scientists, and other disciplines connected to criminology; however, it must be brought to the attention of economists, too, in particular for two reasons. Firstly, a lot of money is invested in fighting against corruption in both developed and developing countries. Secondly, a good deal of public money is gobbled up by corruption in these countries as well. It is necessary to cover economic transformation more with the issue of countering corruption efforts to prevent post-communist societies from a post-transformation ebb to the culture of disregard to corruption. This is the only way to a sustainable society and developed economy in the long run. The paradoxical thing is that the countries that are in the process of transformation of their economy are not very much interested in the topic of corruption despite the fact that it is the corruption that makes them not competitive and it significantly deteriorates their transformation processes.

Taking into account both the WGI results and the results of the analysis of the discourse on corruption in WoS, the so-called East and the West have not converged yet enough in the process of corruption transformation but they have stayed isolated, which is essentially influenced by the underlying cultural patterns in the region. Another question is who should be responsible for changing these cultural values that are responsible for perceiving corruption as something natural. There must be someone who will have an impact on the processes in these societies - if there is a force that exerts its strength towards the desired aim, it will construct the world in an intended way, otherwise, individuals and whole societies will just repeat the things that are not desired from the wider societal perspective. Further research should be oriented in these areas that have not yet been tackled by this research, such as the papers not included in the researched database, i.e., WoS. However, this task will be very complicated if feasible at all. In order to utilize the potential of commercial products, such as Scopus, WoS, or social media such as the Google Academia, the ResearchGate, we hope, that their proprietors will start indexing their product in a data format friendler for PRISMA analysis [28]. In particular, that may be useful for international organizations pushing the anti-corruption agenda and running WoS and Scopus journals in order to drag more academics of the East in a game.

Corruption in post-communist countries is persistent [35]. If the West publishes about corruption and thus creates a solid social discourse about the issue and the East is silent, then it will be almost impossible to accept the anticorruption 
values globally. The attention of the scholars should be shifted from the western countries that should enable the rest of the world to publish in high key journals in the west so that the global community would see the significance of the topic from the global perspective. The local experts will always be easily accepted than an implemented opinion from the West. In summary, this is the way to a sustainable society from the perspective of corruption on a regional and global scale.

\section{8- Declarations}

\section{8-1- Author Contributions}

Conceptualization, B.P. and M.P.; writing—original draft preparation, B.P. and M.P.; writing—review and editing, B.P. and M.P. All authors have read and agreed to the published version of the manuscript.

\section{8-2- Data Availability Statement}

Data sharing is not applicable to this article.

\section{8-3- Funding and Acknowledgements}

This research was funded by the SPEV 2021/2104 project run at the Faculty of Informatics and Management at the University of Hradec Kralove. The authors would like to thank student Ales Berger for his help with data collection.

\section{8-4- Conflicts of Interest}

The authors declare that there is no conflict of interests regarding the publication of this manuscript. In addition, the ethical issues, including plagiarism, informed consent, misconduct, data fabrication and/or falsification, double publication and/or submission, and redundancies have been completely observed by the authors.

\section{9- References}

[1] Buriánek, Jiří. "Tolerant Towards Crime, Concerned with Corruption: The Czech Case." Revija za kriminalistiko in kriminologijo/Ljubljana 65, no. 4 (2014): 382-394.

[2] Krulichová, Eva, and Jiří Buriánek, eds. Obavy ze zločinu: mýty a realita. Charles University in Prague, Karolinum Press, 2020.

[3] Langr, Ivan. "Systémová Korupce Jako Empirický Výzkum: Př́ípad Města Liberec.” Středoevropské Politické Studie Central European Political Studies Review 16, no. 1 (April 1, 2014): 1-28. doi:10.5817/cepsr.2014.1.1.

[4] Frič, Pavol, ed. Czech Elites and the General Public: Leadership, Cohesion and Democracy. Karolinum Press, 2010.

[5] Mungiu-Pippidia, A. Dusub, E.A. Civil society and control of corruption: Assessing the governance of Romanian public universities. International Journal of Educational Development. 2011, 31(5), 532-546. doi:10.1016/j.ijedudev.2010.03.016.

[6] Special Eurobarometer 502, Corruption, 2020. Available online https://data.europa.eu/euodp/en/data/dataset/S2247_92_4 _502_ENG. (accessed on 25 May 2020).

[7] Klitgaard, R. Universities Have the Responsibility to Tackle the World's Toughest Problems. The Chronicle of Higher Education. (2008), 54(21), A.36.

[8] A comprehensive EU anti-corruption policy. Available online: https://eur-lex.europa.eu/legal-content/EN/TXT/?uri= LEGISSUM \%3 Al33301. (accessed on 25 May 2020).

[9] The Stockholm Programme. Available online: https://eur-lex.europa.eu/LexUriServ/LexUriServ.do?uri=OJ:C:2010: 115:0001: 0038:EN:PDF. (accessed on 25 May 2020).

[10] Sajó, András. Corruption, Clientelism and the Future of the Constitutional State in Eastern Europe. East European Constitutional Review, 1998, 7 (2), 37-46.

[11] Horton, P.B., Leslie, R.L, Larson, R.F, and Horton, R.L. The Sociology of Social Problems. New Jersey: Prentice Hall, 1997.

[12] Van Zomeren, Martijn, Tom Postmes, and Russell Spears. "Toward an Integrative Social Identity Model of Collective Action: A Quantitative Research Synthesis of Three Socio-Psychological Perspectives.” Psychological Bulletin 134, no. 4 (July 2008): 504-535. doi:10.1037/0033-2909.134.4.504.

[13] Sørensen, Jarle Løwe, Ann Mari Nilsen Gaup, and Leif Inge Magnussen. "Whistleblowing in Norwegian Municipalities—Can Offers of Reward Influence Employees' Willingness and Motivation to Report Wrongdoings?” Sustainability 12, no. 8 (April 24, 2020): 3479. doi:10.3390/su12083479.

[14] Venâncio de Vasconcelos, Mafalda. "Political Stability and Bank Flows: New Evidence." Journal of Risk and Financial Management 13, no. 3 (March 16, 2020): 56. doi:10.3390/jrfm13030056.

[15] Pertiwi, Kanti. "Contextualizing Corruption: A Cross-Disciplinary Approach to Studying Corruption in Organizations." Administrative Sciences 8, no. 2 (April 10, 2018): 12. doi:10.3390/admsci8020012. 
[16] Vveinhardt, Jolita, and Włodzimierz Sroka. "Nepotism and Favouritism in Polish and Lithuanian Organizations: The Context of Organisational Microclimate.” Sustainability 12, no. 4 (February 14, 2020): 1425. doi:10.3390/su12041425.

[17] Pernica, Bohuslav. The Evaluation of the Programme for Criminality Prevention in the Czech Armed Forces. 2019, Scientific Papers of the University of Pardubice, Series D. Faculty of Economics and Administration. 27(1), (2019).

[18] Pernica, Bohuslav. "The Czech Defence and Security Industry: Taking the Pulse to an Ailing Man.” Defense \& Security Analysis 36, no. 2 (April 2, 2020): 234-244. doi:10.1080/14751798.2020.1750186.

[19] Klitgaard, R. E.. Leadership under systemic corruption. Paper presented at Global Integrity Alliance Meeting of Mekong Delta Countries, Vientiane, Laos. 2004, December. Available online: http://auxbeacon.org/wp-content/uploads/2016/03 /corruption22.pdf. (accessed on 25 May 2020).

[20] GRECO Members and Observers. Anailable online: https://www.coe.int/en/web/greco/structure/member-and-observers. (accessed on 20 August 2020).

[21] The Worldwide Governance Indicators. Available online: http://info.worldbank.org/governance/wgi/. (accessed on 20 October 2020).

[22] Hilgartner, Stephen, and Charles L. Bosk. "The Rise and Fall of Social Problems: A Public Arenas Model." American Journal of Sociology 94, no. 1 (July 1988): 53-78. doi:10.1086/228951.

[23] Dorr, Sarah. "The Scopus Diaries and the (il)logics of Academic Survival. A Short Guide to Design Your Own Strategy and Survive Bibliometrics, Conferences, and Unreal Expectations in Academia.” Eurasian Geography and Economics 62, no. 1 (January 27, 2020): 128-129. doi:10.1080/15387216.2020.1721308.

[24] Godemann, Jasmin, Jonas Haertle, Christian Herzig, and Jeremy Moon. "United Nations Supported Principles for Responsible Management Education: Purpose, Progress and Prospects.” Journal of Cleaner Production 62 (January 2014): 16-23. doi:10.1016/j.jclepro.2013.07.033.

[25] Hauser, Christian. "Reflecting on the Role of Universities in the Fight Against Corruption." RAUSP Management Journal 54, no. 1 (February 11, 2019): 4-13. doi:10.1108/rausp-09-2018-0080.

[26] Lewis, Jacob S. "Corruption Perceptions and Contentious Politics in Africa: How Different Types of Corruption Have Shaped Africa's Third Wave of Protest.” Political Studies Review (May 7, 2020): 147892992090365. doi:10.1177/1478929920903657.

[27] Gorsira, Madelijne, Linda Steg, Adriaan Denkers, and Wim Huisman. "Corruption in Organizations: Ethical Climate and Individual Motives.” Administrative Sciences 8, no. 1 (February 19, 2018): 4. doi:10.3390/admsci8010004.

[28] Moher, David, Alessandro Liberati, Jennifer Tetzlaff, and Douglas G. Altman. "Preferred Reporting Items for Systematic Reviews and Meta-Analyses: The PRISMA Statement." PLoS Medicine 6, no. 7 (July 21, 2009): e1000097. doi:10.1371/journal.pmed.1000097.

[29] Sinay, Laura, Rodney William Carter, and Maria Cristina Fogliatti de Sinay. "In the Race for Knowledge, Is Human Capital the Most Essential Element?" Humanities and Social Sciences Communications 7, no. 1 (July 8, 2020). doi:10.1057/s41599-0200521-5.

[30] Bortolus, Alejandro. "Running Like Alice and Losing Good Ideas: On the Quasi-Compulsive Use of English by Non-Native English Speaking Scientists.” AMBIO 41, no. 7 (September 7, 2012): 769-772. doi:10.1007/s13280-012-0339-5..

[31] Angermuller, Johannes. "Accumulating Discursive Capital, Valuating Subject Positions. From Marx to Foucault." Critical Discourse Studies 15, no. 4 (April 5, 2018): 414-425. doi:10.1080/17405904.2018.1457551.

[32] Zaloznaya, Marina, Vicki Hesli Claypool, and William M Reisinger. "Pathways to Corruption: Institutional Context and Citizen Participation in Bureaucratic Corruption.” Social Forces 96, no. 4 (February 16, 2018): 1875-1904. doi:10.1093/sf/soy007.

[33] Zhang, Nan. "Institutions, Norms, and Accountability: A Corruption Experiment with Northern and Southern Italians.” Journal of Experimental Political Science 5, no. 1 (December 4, 2017): 11-25. doi:10.1017/xps.2017.26.

[34] Ives, Bob, Madalina Alama, Liviu Cosmin Mosora, Mihaela Mosora, Lucia Grosu-Radulescu, Aurel Ion Clinciu, Ana-Maria Cazan, et al. "Patterns and Predictors of Academic Dishonesty in Romanian University Students." Higher Education 74, no. 5 (November 25, 2016): 815-831. doi:10.1007/s10734-016-0079-8.

[35] Reis, João Carlos Gonçalves dos. "Politics, Power, and Influence: Defense Industries in the Post-Cold War." Social Sciences 10, no. 1 (January 6, 2021): 10. doi:10.3390/socsci10010010. 